\title{
Management of Interface between Main Contractor and Subcontractors for Successful Project Outcomes
}

\author{
Harry White $^{1}$ and Ramesh Marasini ${ }^{2}$ \\ ${ }^{1}$ Site Manager, Mansell Construction Services Limited, Roman House Salisbury Road Totton Southampton, SO40 3XF, \\ E-mail: hwhite@mansell.plc.uk \\ ${ }^{2}$ Associate Professor, Maritime and Technology Faculty, Southampton Solent University, East Park Terrace Southampton, \\ SO14 0RD, E-mail: ramesh.marasini@ solent.ac.uk (corresponding author).
}

Project Management

Received June 10, 2013; received revision September 8, 2013; accepted September 22, 2013

Available online December 19, 2013

\begin{abstract}
There has been increased dependence on subcontracting within the construction industry, the operational relationship between the Main Contractor (MC) and Subcontractor (SC) plays a significant role in successful delivery of projects. Through the literature review this paper argues that despite SCs bring added value to construction projects, the increased reliance on SCs has strained relationships between the MC and SC. Also MCs are more concerned with risk and price reduction which undermine the relationship heavily. Current practices in the construction industry in managing SCs were evaluated through a case study and semi-structured interviews. A questionnaire survey was used to investigate the ways of facilitating the interface between the MC and SC in general. The study highlighted that prevailing adverse relationships and culture in the industry are influencing the success of construction projects. The lack of trust is a key factor affecting the relationships between MC and SCs. However, the proactive involvement of the MC with SCs in maintaining continuity of the team from procurement to construction stage and transparency in the processes were key success factors for successful completion of the project.
\end{abstract}

Keywords: Construction, interface management, main contractor and subcontractor relations.

\section{Introduction}

Construction projects have become more complex and challenging owing to the technical advances, tighter regulations and need for effective management of resources for competitive edge. With the increased complexity of construction projects, the role of Subcontractor (SC) has been dominant in the construction project under the leadership of MCs. The Main Contractor (MC) concentrates efforts towards organisational management to meet the needs of the client while the SC specialises in particular project aspects to meet the needs of the MC (Jamieson et al., 1996). Clients demand the most appropriate method of procurement and strategy to mitigate the effects of time and cost overruns on construction projects and continue towards success (Okunlola and Johnson, 2013) while the MC may adopt a less sophisticated approach to the procurement of the SC.

Artto et al., (2008) emphasised that the MC needs to focus on inter-organizational relationships and not just focus on the individual SC's capabilities. The influential reports of Latham (1994) and Egan (1998) suggested ways for improving construction industry performance and emphasised a need to focus on integration of processes across companies, and on building close relationships. It is acknowledged that some of the principles outlined in the reports, have made little or no change, especially further down the supply chain. Wolstenholme et al., 2009 highlight that construction industry requires radical change but the industry is not doing enough to embrace such change. There is a general consensus that relationships amongst MC and SCs have a significant effect on the success of the project, but, the topic of SC management has been neglected (Moody, 2008) and the key operational interface between the MC and SCs has been undermined (Humphreys et al., 2003).

The management of $\mathrm{MC} / \mathrm{SC}$ interface has found less attention and is generally unequal between the parties given the dependence of the SC on the MC for work (Odeyinka and Kelly, 2009). SCs generally operate within a certain geographic radius which restricts bidding opportunities made available by limited MCs. The SCs are likely to continue to receive requests for future projects by maintaining good relations with the MCs (McCord, 2010).

During the procurement stage, roles and responsibilities of the SC are defined but many issues arise during construction, often affecting project continuity. The objective of this paper is to identify MC and SC interface variables and their impact on successful completion of projects evaluating procurement and construction stages. Through the literature review, the 
variables that influence the relationship between the MC and $\mathrm{SC}$ were established. Data were collected using a case study. Interviews of the MC and SC managers and a questionnaire survey of SCs involved in the case study project were carried out to triangulate the findings. This paper argues that early involvement of SCs and communication and co-ordination established during the procurement stage will create a better working relationship between MC and SCs throughout the rest of the project.

\section{Factors Impacting MC/SC Interface}

Relevant papers in the area of construction project management mainly related to $\mathrm{MC}$ and SC relationships were reviewed and key words or factors that were used in the papers were collected. The analysis and grouping of the words resulted into eight main variables, which are presented in Table1. The variables are: (1) Trust (2) Price (3) Early Involvement (4) Communication (5) Project Management (of subcontract work) by the MC (6) Transparency (7) Quality (8) IT support and facilitation. The column numbers in Table 1 represent the above factors, which are further evaluated in the following sections.

Table 1. Factors influencing MC/SC interface

\begin{tabular}{|c|c|c|c|c|c|c|c|c|}
\hline Authors/ Factors & 1 & 2 & 3 & 4 & 5 & 6 & 7 & 8 \\
\hline Artto et al., ( 2008) & & $\mathrm{x}$ & & & $\mathrm{x}$ & & $\mathrm{x}$ & \\
\hline Ashworth (2006) & & & & & $\mathrm{x}$ & & & \\
\hline Ballard \& Howell (2004) & & & & $\mathrm{x}$ & $\mathrm{x}$ & & & \\
\hline Bankvall et al., (2010) & & & & $\mathrm{x}$ & & & & \\
\hline \multicolumn{9}{|l|}{ Briscoe ( 2001) } \\
\hline Briscoe ( 2005) & $\mathrm{x}$ & & & & & & & $\mathrm{x}$ \\
\hline Cooke \& Williams (2004) & & $\mathrm{x}$ & $\mathrm{x}$ & $\mathrm{x}$ & $\mathrm{x}$ & & $\mathrm{x}$ & \\
\hline Dainty (2001) & $\mathrm{x}$ & & & $\mathrm{x}$ & $\mathrm{x}$ & $\mathrm{x}$ & $\mathrm{x}$ & $\mathrm{x}$ \\
\hline Das and Teng, (1998) & & & $\mathrm{x}$ & & & & & \\
\hline Fearne \& Fowler, (2006) & & & & $\mathrm{x}$ & & & & \\
\hline Fryer (2004) & & & $\mathrm{x}$ & $\mathrm{x}$ & $\mathrm{x}$ & & & \\
\hline Hadaya \& Pellerin (2010) & & & & & & & & $\mathrm{x}$ \\
\hline Hartmann \& Caerteling (2010) & $\mathrm{x}$ & $\mathrm{x}$ & & & $\mathrm{x}$ & & $\mathrm{x}$ & \\
\hline Humphreys et al., (2003) & $\mathrm{x}$ & $\mathrm{x}$ & & & & & $\mathrm{x}$ & \\
\hline \multicolumn{9}{|l|}{ Jamieson ( 1996) } \\
\hline Latham (1994) & $\mathrm{x}$ & $\mathrm{x}$ & $\mathrm{x}$ & $\mathrm{x}$ & $\mathrm{x}$ & & $\mathrm{x}$ & \\
\hline Lossemore et al., (2000) & & & & $\mathrm{x}$ & $\mathrm{x}$ & & & \\
\hline Love (2004) & & & & $\mathrm{x}$ & $\mathrm{x}$ & & & \\
\hline \multicolumn{9}{|l|}{ Matthews (1996) } \\
\hline Mawdesley et al., (1998) & & $\mathrm{x}$ & & $\mathrm{x}$ & $\mathrm{x}$ & & & \\
\hline McCord ( 2010) & & & & & $\mathrm{x}$ & & & \\
\hline McGeorge and Palmer (1997) & & & & $\mathrm{x}$ & $\mathrm{x}$ & & $\mathrm{x}$ & \\
\hline Mclvor et al., (1997) & & & & & & $\mathrm{x}$ & & \\
\hline Miller et al., ( 2002) & $\mathrm{x}$ & $\mathrm{x}$ & & & $\mathrm{x}$ & $\mathrm{x}$ & & \\
\hline Muya et al., (1999) & & $\mathrm{x}$ & $\mathrm{x}$ & $\mathrm{x}$ & $\mathrm{x}$ & & & \\
\hline Ndekugri \& McCaffer (1998) & & & & & & & & $\mathrm{x}$ \\
\hline Odeyinka \& Kelly (2009) & & & $\mathrm{x}$ & $\mathrm{x}$ & $\mathrm{x}$ & & & \\
\hline Segerstedt \& Olofsson (2010) & & & & & $\mathrm{x}$ & & & \\
\hline Thorpe et al., (2003) & $\mathrm{x}$ & & & & $\mathrm{x}$ & & & \\
\hline Xie et al., (2010) & & & & & $\mathrm{x}$ & & & \\
\hline Total & 7 & 8 & 6 & 13 & 19 & 3 & 7 & 4 \\
\hline
\end{tabular}




\subsection{Trust}

Humphreys et al., (2003) suggested that a major requirement for success in a MC and SC relationship is trust. While McIvor et al., (1997) presented evidence which suggested that a conflict of interests within the MCs organisation could prevent SC integration. Hartman and Caerteling, (2010) discussed the importance of both price and trust in the selection of Subcontractors and concluded they were both important mechanisms. Miller et al., (2001) suggests the prevalence of unfair practices has increased, resulting in dispute and conflict descending from financial self-interest between various stakeholders within the process. Dainty et al., (2001a), explained how Subcontractors relationships with Main Contractors over many years could easily be destroyed as soon as something went wrong. Additionally, many small to medium sized SC organisations feel long term partnerships with a specific MC could mean they lose work with other Main Contractors.

\subsection{Price}

Humphreys et al., 2003 stated how MCs see the greatest potential for cost savings through the use of SC's. The assessment of tenders should consider both quality and price from a suitable number of compliant tenders (Code of Practice for the Selection of Subcontractors, 1997). Although MCs regard the advantages of immediate cost savings through the SC to outweigh the possibility of reducing risk and transaction costs, regardless of being known or unknown (Hartman and Caerteling, 2010).

Adverse relationships developed during the tender can result in serious payments problems for Subcontractors (Dainty et al., 2001b). The subcontractors are not paid promptly. The Construction Act 2009 addresses previous deficiencies complained of in the 1996-1998 Acts, although amended provisions are not straightforward enough for Subcontractors to gain the most from.

\subsection{Early Involvement (During Main Contractor's Tender and Initial Stages of the Project)}

It is essential that good communications are established from the outset and that MC and SCs have continual and direct contact throughout the entire Subcontractor period (Fryer, 2004). Cooke and Williams, (2004) would agree and believe good liaison and mutual respect must be established early in the contract period which is developed through regular co-ordination meetings.

The Code for the Selection of Subcontractors, (1997) expressed the need for Main Contractors to ensure their requirements are fully explained to the potential Subcontractor. Although Odeyinka and Kelly (2009) suggested the tender documentation sent to the Subcontractor during the procurement phase will frequently miss out key specification information, despite the Main Contractor knowing more about various issues in relation to the project, such as specification and design.

The full involvement of Main Contractors and key Subcontractors at the earliest point in the project are crucial for success (Murray et al., 1999). In many circumstances the MC will invite tenders from SCs, at a stage when they themselves are not, or may never be appointed to undertake the work (Code for Selection of Subcontractors, 1997). During the tender process Subcontractors should be asked if they are willing to tender, allowing information about the Subcontractors current anticipated capacity and enthusiasm for the proposed works to be clarified. MC require confidence that SCs are able and willing to deliver their services according to project specification (Das and Teng, 1998).

In addition, time available for tendering and information is not under the direct control of the MC, therefore insufficient time or information by a client for tender preparation, will affect the effectiveness of the SC selection (Code for Selection of Subcontractors, 1997). MC rushed to prepare their documents, will undoubtedly place that pressure upon the SC (Latham, 1994).

\subsection{Communication}

Communication with SC demands special attention. The sub-contract site personnel have responsibilities, both to their own company and to the $\mathrm{MC}$, so that lateral and downward communications "compete" for priority. This can be an issue for any organisation, as there is a heavy reliance on contract documents to define duties and obligations of the contractor and Subcontractor (Fryer, 2004). Fearne and Flower, (2006) described the lack of coordination and communication integrated with adversarial and disjointed relationships between involved parties as a primary reason for the perceived poor supply chain.

\subsection{Project Management of Subcontract Work}

The planning of subcontracted work is just as important as planning of the MCs own labour and plant. This is because the SC's work impinges on the work of others on site. Realistic planning of the work provides a base, against which pro-active control and re-active control can be carried out to ensure timely completions of the work (Mawdesley et al., 1998). Although Ballard and Howell's (2004) analysis revealed that the large majority of plan failures were within the MC control, contradicting traditional assumption that variability was from external causes.

Dainty et al., (2001a) found that smaller subcontracting companies felt that programming time is becoming unrealistic resulting in poor quality, latent defects and complained of being expected to be flexible with no acknowledgement of their own business requirements. The problems were considered surprising given the availability of information and communication technology. They concluded no effort had been made to align the systems of SCs with MCs, or implement the skills needed to avoid such problems.

Bankvall et al., (2010) recognised little attention has been paid towards the MC and SC relationships. Artto et al., (2008) emphasised that the MC needs to focus on SCs inter-organizational relationships and not just focus on the individual SC's capabilities. Mawdesley et al., (1998) stated that it is essential to not only manage the interface between both the MC and the SC but also, between the SCs themselves. The MC and SC relationship needs to be maintained throughout procurement and construction to enable a strong interface within the project team, which signifies a positive move away from the traditional adverse relationships.

\subsection{Transparency}

McIvor et al., (1997) presented evidence which suggested that a conflict of interests within the MCs organisation 
could prevent SC integration. Procurement personnel find the area of cost transparency difficult, because open book negotiations are not used for mutual benefit, but used as a method for reducing margins. In the context of construction, the negative working behaviour is affected by those working approaches. The relationships are dominated by the relative and perceived power of participants. Adverse relations developed during the tender process results in serious problems during the construction phase (Dainty et al., 2001b).

Miller et al., (2001) described how direct costs associated with co-ordination, scheduling, supervision and enforcement of contract terms can be budgeted into total project costs, it is far more difficult to estimate the indirect costs that arise from motivational issues, opportunism and conflict. Miller et al further state that costs occur primarily from failing to acknowledge that small subcontracting firms are individual decision making entities.

\subsection{Quality}

The MCs success on projects relies on the temporary bounded interdependent services of the SCs. Because the services have not yet been performed, it remains difficult for the Main Contractor to accurately evaluate in advance the motives and intentions of the Subcontractor because their quality of resources, assets and capabilities are unknown (Ngowi and Pienaar, 2005). Nevertheless, the $\mathrm{MC}$ is willing to compromise on technical know-how and co-operative skills, as long as the Subcontractor's quality is acceptable to achieve market-conform price (Hartmann and Caerteling, 2010).

\subsection{IT Support and Facilitation}

Ndekugri and McCaffer (1998) study defined inefficient information management within contracting organisations, as a prolonged challenge to the construction industry. In contrast integrated information and communication is described within supply chain management (SCM) literature as the primary driver of value, innovating open communication will enhance trust and collaboration. The point is illustrated through Briscoe et al., (2005) research. Effective communication systems will ensure reliable flows of information that establish mechanisms for problem resolution through tiers of the supply chain, generating added-value into projects.

Information technologies (IT) can benefit the construction industry by linking the Main Contractor and Subcontractor, reducing the response time and enabling companies to expand, but studies have revealed IT is used less in the construction industry compared to other industries (Hadaya and Pellerin, 2010). Dainty et al., (2001b) converses many SCs complain of an inadequate knowledge management by the MC, causing an impact on the quality of their work (Hartmann and Caerteling, 2010).

\section{Research Strategy: Case Study, Interviews and Questionnaire Survey}

The research strategy used in this study involved a case study, semi-structured interviews of MC/SC managers and questionnaire survey of subcontractors. The single case study was used to collect facts and documentation to study a typical live project; semi-structured interviews were used to investigate the relevance of variables identified through the literature review. An online questionnaire survey was used to elicit the opinions of local subcontractors and triangulate the findings from the literature review, case study and semi-structured interviews.

\subsection{Case Study Background}

A detailed Case Study of a live project, a Sea Survival Training Centre (SSTC) with a project value of $£ 2 \mathrm{M}$ was selected. The MC involved specialises in building works with a turnover of $£ 800 \mathrm{M}$, which is part of an international construction group. The SSTC project was procured under the Works Enabling Agreement, which included a wide range of small to medium sized, local SCs. The project documents such as drawings, specifications, contract documents and communications during procurement and construction stages were collected from the MC. A SC involved in roofing and cladding was selected as this work was progressing during the period of study. Detailed information about the processes followed during procurement and construction was elicited from site documents, exploratory discussions, direct observations and participant observations.

The objective of the Case Study was to carry out an indepth analysis to establish key variables that need to be managed for a successful project outcome. The variables were investigated further through semi-structured interviews. This was followed by an online questionnaire to triangulate the findings.

\subsection{Semi-structured Interviews}

Semi-structured interviews were conducted with three key personnel from the MC namely Senior Site Manager, Quantity Surveyor and Senior Procurement Surveyor. Six SCs personnel namely Contracts Manager, Quantity Surveyor and four Managing Directors involved in SSTC project. The MC's Project Manager had 9 year experience with the current company; Quantity Surveyor had more than 5 year experience dealing with day to day running of SCs. The Senior Procurement surveyor was working with the company for more than 2 years. All the SCs interviewed hold management positions and have worked with the MCs frequently, experience ranged from 8-20 years.

The objective of interviewing managers from both MC and SCs in the Case Study project was to obtain views from both sides so that an unbiased conclusion can be drawn and justify the findings of the SC presented earlier are representative.

\subsection{Questionnaire Survey}

An online questionnaire survey with 15 questions was sent to $98 \mathrm{SCs}$ and 18 responses were received. The objective of the survey was to validate the factors highlighted by the Case Study and interviews. The majority of SCs who responded to the questionnaire survey are involved in the superstructure work of construction. Relevant questions and responses are included in this paper.

\section{Case Study Findings on The Processes Involved in the Subcontract Work}

\subsection{Procurement}

The MC put a package together for roofing and cladding and sent out a formal inquiry with drawings, specification and bill of quantities. During the estimating and pricing by the SC, it occurred that some items were not measured on the drawing and hence not included in the bill of quantities. 
The SC withheld the information about the potential additional items to achieve a competitive price against the bill of quantities. Adversarial relations between the MC and SC were evident through the method of the SC's approach which also revealed lack of trust and total honesty even though the SC was part of MC's supply chain.

\subsection{Pre-contract Stage}

Once the MC had won the project, the SC was asked to clarify the original tender price with the latest fully appraised information. The SC's Managing Director and team leader were invited to a pre-contract meeting with the procurement team. Negotiations were conducted on aspects of the project to find out exactly what has been offered, and for what price. Other aspects included the evaluation of SC's ability to meet timescales, work programme, lead times and current workload.

After negotiations, a price was agreed and terms and conditions were finalised. An order was placed with the SC. Then SC was invited back for a pre-let meeting to go through a Subcontract Management Plan and Domestic Subcontract Order. The meeting was attended by the members of the site management and procurement teams. This meeting was also used to create clear understanding of agreed terms. The key documents used at this stage were: Works Enabling Agreement, Subcontract Pursuant to Main Contract, Drawings, Specifications, Schedule of Rates, SC Management Plan, Project Management Plan and schedules, Standard Risk Control Arrangements and SC Payment Timetable.

Soon after the order was placed the SC ordered materials to suit the MC's programme. Then the SC received design and architect drawings and started to work on construction drawings. The construction work commenced on site without any issues.

\subsection{Construction Stage}

Once the workforce arrived on site they received a full site induction and were asked to check and sign their method statements and risk assessments, a requirement of the MC. The SC passed drawings and specifications; communicated only work related information to the workforce, who did not pay full attention to the method statements or risk assessments.

During the course of construction the SC raised a number of variations, on inspection of the architect's drawings in further detail. The issue was resolved through negotiations, and it was agreed to price on a lump sum basis which ultimately reduced the risk for the MC. Despite the SC recognising potential variations during procurement, the SC did not raise or discuss the variations at the procurement stage as this would increase their tender price.

It was discovered that the design of the Canopy, a key element, included an outline design; details were not available as the designer wasn't knowledgeable on this particular issue. To ensure continuity in the project, the MC had to take a proactive role to co-ordinate with the design team; produce design drawings spending time and money to resolve the issue as soon as possible. The MC decided to bear the costs of correcting and developing the design to keep the contracts continuing as the issue didn't come under the Works Enabling Agreement.
The SCs programme was delayed through issues aligning the steel, preventing work being carried on the cladding rails. Another delay was caused from late window installation, despite the issue being raised much earlier. However, the MC's site management communicated to the SC constantly and played a proactive role to resolve the issues. This allowed the SC to re-direct their workforce to maintain workflow, avoiding confusion and maintaining a good relationship. Despite the problems, the completion of the SC's package was achieved through close co-ordination and management.

\section{Analysis of Semi-structured Interviews}

Appendix 1 provides a list of questions used in the semistructured interviews. The interviews were transcribed and were analysed using a template approach with a list of analysis variables and findings which are presented in the following sections with a comparison of variables identified through literature presented in Table 1.

\subsection{Trust}

Lack of trust is an issue. SCs normally miss items that require the $\mathrm{MC}$ to interrogate quotations, negotiation becomes essential. "..it's human nature, if you have a personal relationship with somebody, you need to talk to them and communicate with them in a respectful way, 9/10 you will get respect back from them, instead of leaving arguments to the last minute, you can sit down with them iron them out, ...nothing is worse than something going wrong and the SC not telling you what's happened. We don't know what's going on, trying to argue over money, whose fault it is, it's so much easier to be on respectful talking terms in the first place". One of the interviewees' stated that "an honest SC is a good contractor."

\subsection{Price}

Normally negotiation is on price. All the SCs agreed that this impacts relationships. One SC described, in his own words "relationships can be focused on a take it or leave it attitude...can't see the point, of partnerships or supply chains" However, if it is in the form of value engineering, then it is seen as positive. Also, as one SC highlighted, in certain projects, where pricing is too high, which means the SC can't really do much on it, MC's flexibility and willingness to talk is appreciated by the SCs and negotiation in this case was seen as fair. MC argued that negotiation with SCs was seen as essential in order to find out what they are offering, clear up any misunderstanding between what you think their quote says and what they think they are offering, what they have actually included and more importantly what they have excluded and can they do the work within the timescale.

Some concerns regarding the management of variations were raised by SCs. Two subcontractors in their interview highlighted delays in finalising payment when there are variations. In their words, one stated that "you don't ever really get the value of a variation because it has a knock on effect, quantity surveyors won't let you claim for travel or other expenses (overheads)"; the other SC highlighted "when a variation is submitted, you find you spend a lot of your time justifying work already done a couple of months later down the line, which is frustrating for a sub-contractor." The MC explained that procurement team interrogates the SC's quote during negotiation to 
discover what the price has included for, in an attempt to prevent the SC coming back with variations.

\subsection{Early Involvement (During Main Contractor's Tender and Initial Stages of the Project)}

\subsubsection{Early involvement and pre-contract planning}

Both MC and SCs highlighted the importance of precontract meeting to understand the project, develop management strategy. SCs emphasised that knowing MC requirements and practices was essential to identify the right team for the job. SCs were involved from the beginning of the procurement process; 4 out of 6 of the more complex packages attended a pre-contract meeting to discuss various aspects of the project with the procurement team. Some went straight to pre-let meetings to discuss aspects of the project with the site management team after the procurement team had been in contact.

\subsection{Communication}

The communications aspects were analysed under three factors.

\subsubsection{Information supplied during procurement stage}

MC highlighted that the information supplied during the procurement stage would include drawings, specifications, subcontract management plan including Health \& Safety plan; all the site records (soil reports where applicable), company's standard documents and background documentation. Normally bill of quantities (BOQ) are provided for re-measurable contract and SCs price up. However, one SC stated that "On this project, it was just drawings and there was no BOQ, we would have made our own bill up and specification, drawings were not that detailed".

\subsubsection{Detail of information}

MC sent information normally in electronic form; SCs had to troll through all information as MC covered themselves (sent all information, don't miss anything). One SC stated "because there could be a drawing, we have missed because we don't think it's relevant, it gets missed and we price, so we then put drawing numbers to what we have price to". Sometimes any missed information can be claimed from the client, sometimes it's a loss to MC or SC, if it has been included in the specification. The MC clarified that all information is sent mainly for lump sum packages. One of the interviewee stated "The information provided can be subjective to the evaluation of risk. If the subcontractor package is complex then often the contract will be lump sum. This transfer of risk requires all the information to be provided during the procurement process." On the similar note, 2 out of 6 subcontractors interviewed highlighted difficulties in processing the volume of information, often not concerning their packages.

\subsubsection{Communication during construction stage}

In the beginning of the project when there are fewer SCs on site, communication is good. As the project progresses, more trades on site, the information provided will reduce. Updated drawings, specifications and programme are usually communicated. However, the information passed to the site team was variable. Four of the subcontractors interviewed described only drawings and specifications were passed down to the workforce on site. Whilst other two described the use of other documents received from the MC including method statements, and risk assessments to communicate project information.

All Subcontractors agreed the regular flow of information from the Main Contractor during the construction process contributed to a managed site, although they did describe how information flow could vary. Often as site trades increased, information flow would lessen.

\subsection{Project Management and Complexity of Projects}

\subsubsection{Subcontract process}

The interviewee confirmed subcontract process used in projects mainly followed a standard process. The MC sent inquiry's to 3-4 or 6-8 SCs depending on the complexity. The MC used supply chain database or found SCs from other sources that were suitable; negotiation was carried out once SCs submitted the price.

\subsubsection{Lead in times}

SCs do not get sufficient time to provide a decent tender, and are always under pressure as many inquiries keep coming. One subcontractor highlighted poor fabrication of materials and short leading time provided by the MC caused installation problems on site. This caused delays to programme, contributing to extra operatives on site and working out of sequence caused extra costs.

\subsubsection{Coordination}

One of the interviewees' highlighted: 'It's quite a tight bit of coordination so, it's getting all parties in as well to make sure they all clearly understand where their responsibilities lie, make sure there all communicating together to also understand each other's part of the contract. So depending on how complicated the package is, they might have them in once a week or once a fortnight, making the progress meetings, making sure everyone is happy, everyone understands the programme, everyone knows where they should be working and the process their work involves".

\subsubsection{Strategies to progress with project}

SCs do not provide strategies because they are reliant on the organisational management of the MC.

The SCs highlighted right prices during procurement; good management and co-ordination by the site team; frequent (weekly meetings). with other SCs where trades are dependent and managing variations mutually as key points for success. One of the MC interviewee emphasised that regular meetings with SCs should take place to monitor and provide feedback on their performance and suggest areas of improvement for successful outcome. Often the responsibility of the operational management will be left to the site foreman.

SCs highlighted the factors to improve, in their words, as: 'getting supply chain to get stuff on site and liaising with SCs to do the work; Continuity is the most important thing to us on a job, so you don't have stop starting all the time; more lead in times; regular site meetings; spend time to get design correct before issuing to the site'.

SCs normally involve management team leaders /foreman who are involved during the tender to construction but often have limited involvement during construction, site visits etc. owing to the limited availability of senior managers. MC also viewed that it is 
important to have continuity of the people from procurement to construction. Normally a handover process is used to the site team to brief about the process. The SC management involved during the tender would either pass the information directly to the site foreman or another senior manager. None of the subcontractor's site foremen were involved during the tender stage.

\subsection{Transparency}

During the pre-construction meetings, the roles of the SC will be identified and the attendances of any plant or machinery are agreed prior to construction commencement. The majority of site co-ordination will come during the construction process itself, through regular site meetings organised by the Main Contractor.

Once the contract is won, the MC will have an estimator's handover. This allows the project to be handed over to the project team. During the Case Study project, the site management was involved during the preconstruction meetings with some of the Subcontractors, described as being crucial towards the project. Most of the problems encountered (other than the one discussed in case study section) and variations discussed openly and dealt with. This was regarded as were a success factor in the project.

The MC put a package together for roofing and cladding and sent out a formal inquiry with drawings, specification and bill of quantities. During the estimating and pricing by the SC, it occurred that some items were not measured on the drawing and hence not included in the bill of quantities. The SC withheld the information about the potential additional items to achieve a competitive price against the bill of quantities. Adversarial relations between the MC and SC were evident through the method of the SC's approach which also revealed lack of trust and total honesty even though the SC was part of MC's supply chain.

\subsection{Quality}

The project was completed ahead of schedule and within the budget. The interviews did not raise any significant issues with quality. However one SC, in their own words said "There seem to be a lot of call backs at the end of the job, bits and pieces left at the end, that still need doing, don't really know what it was down to but I spoke to other trades and they also had the same issue" and pointed out the problems with Clerks of Works who was trying to keep client happy by pointing out different things wrong and drag the job out. There seems to be lack of appreciation of the role of the Clerk of Works and differences in quality standards required in a project.

Some SCs who did not complete the work on time or within the budget highlighted the reasons as: quality of the materials supplied by the supplier; design discrepancies; problems with prefabrication in terms of design and accuracy and short lead in times. The interview questions were not focussed on quality much so limited information was available on quality aspects of the project.

\subsection{IT Support and Facilitation}

The semi-structured interviews revealed that a Subcontractor was restricted through the amount of drawings sent through the use of I.T in communication. The interviews revealed that this is a problem for some other Subcontractors.

\section{Key Factors to Improve Relationships and Success on Projects}

The SCs highlighted right prices during procurement; good management and co-ordination by the site team; frequent (weekly meeting) with other SCs where trades are dependent and managing variations mutually as key points for success. The MC interviewee suggested that regular meetings with SCs in order to monitor their performance provide feedback on their performance and suggest areas of improvement as a key point.

SCs highlighted the factors to improve, in their words, as: getting supply chain to get stuff on site and liaising with SCs to do the work; Continuity is the most important thing to us on a job, so you don't have stop starting all the time; more lead in times; regular site meetings; spend time to get design correct before issuing to the site. MC highlighted areas of improvement, in their words, as: improve communication; do not just depend on electronic communication but face-to-face too; and know your SC, have face to face meetings with them before the contract is let.

\section{Questionnaire Survey}

An online questionnaire survey of SCs was carried out. The subcontractors were in contact with a Site Team Quantity Surveyor or Procurement Quantity Survey during the subcontract process. Key questions and responses are included in this paper. Many questions included responses in 5 different scales such as Very Significant, Significant, Neutral, Insignificant and Very Insignificant. A weighted percentage response was calculated using the ordinal ranking method (Eq. 1).

$$
\mathrm{Z}=\frac{\sum X_{i} L_{i}}{N}
$$

Where:

$$
\begin{aligned}
& \mathbf{Z}=\text { Average Rating, } \\
& \mathrm{i}=1,2,3,4,5 \\
& \mathbf{X}_{\mathbf{i}}=\text { No of responses in the category } \mathrm{i} \\
& \mathbf{L}_{\mathbf{i}}=\text { Rating for ' } \mathrm{i} \text { ' (e.g. 5-Very Significant, 4- }
\end{aligned}
$$
Significant, 3-Neutral, 2-Insignificant and 1-Very Insignificant)

\section{$\mathbf{N}=$ Number of responses.}

For other questions, which have less than 5 ordinal scale, the percentage responses for each ordinal values are used to produce graphs and findings are discussed.

$Q:$ What type of procurement strategy is used mainly by the MCs?

The SCs were involved in mixed methods of procurement (with some being involved in single). Negotiation was common to many SCs and partnering was used the least. About $47 \%$ (Fig. 1) of SCs have been involved in supply chain and some used partnering, which highlights the project delivery is moving towards relationship oriented contracts.

Q: Does the Main Contractor involve the Subcontractor early enough, to provide a complaint tender and prepare for the project? 
Fig. 2 responses show the Subcontractor "Sometimes" has enough time to provide a compliant tender. Also "before" and "during the Main Contractor has secured the work", the Subcontractor rarely has enough time to provide a compliant tender. Both the literature review and Case Study highlighted issues of uncertainly affecting documentation while the Main Contractor is securing the work.

Q: What are the implications of your early involvement in the procurement on project delivery? (Responses; Very Important, Important, Neutral, Unimportant, Very Unimportant)

Table 2 presents the factors that SCs were asked to indicate the implication of their early involvement. The average ratings are presented in Fig. 3. Price and completion (within time and budget) are influenced by the early involvement of the SCs and time given to complete the tender. The least influenced are planning and team relationships with $61 \%$ response (Table 2 ).
Table 2. Order of most influenced

\begin{tabular}{cc}
\hline Factors & $\begin{array}{c}\text { Total responses of very } \\
\text { Significant and significant impact }\end{array}$ \\
\hline Price & $94 \%$ \\
Completion & $83 \%$ \\
Variations & $78 \%$ \\
Progress & $78 \%$ \\
Quality & $72 \%$ \\
Communication & $67 \%$ \\
Performance & $67 \%$ \\
Planning & $61 \%$ \\
Team Relationships & $61 \%$ \\
\hline
\end{tabular}

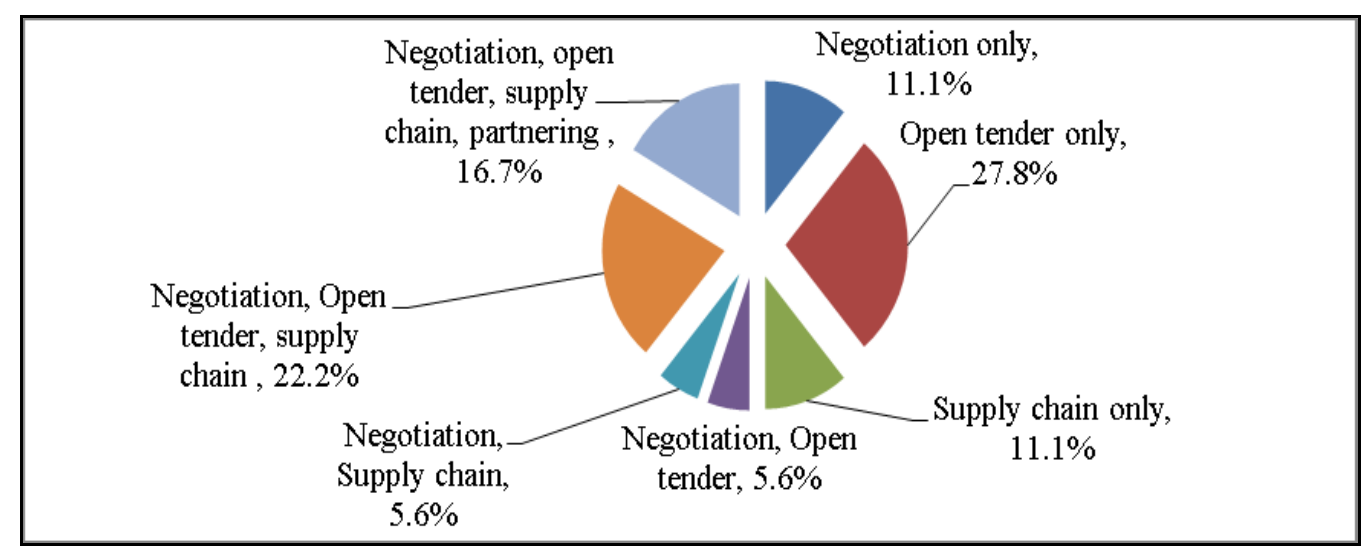

Fig. 1. Procurement strategy by MCs

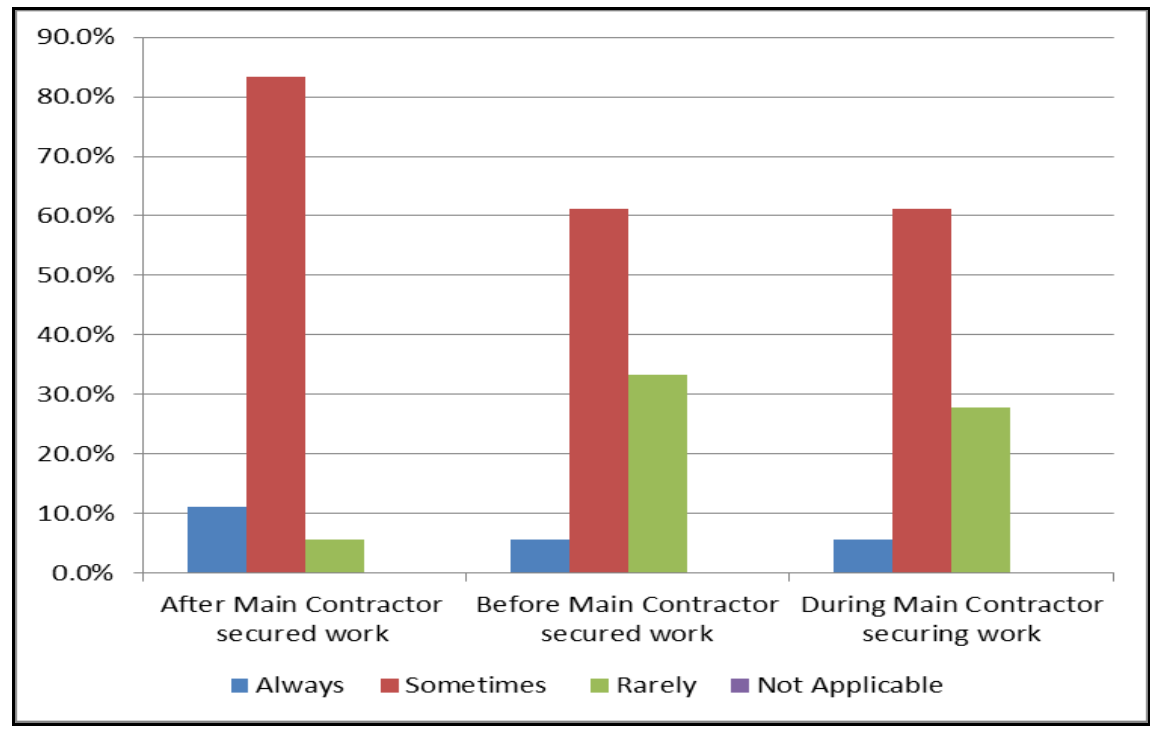

Fig. 2. Lead in time and involvement during tender for subcontractors 


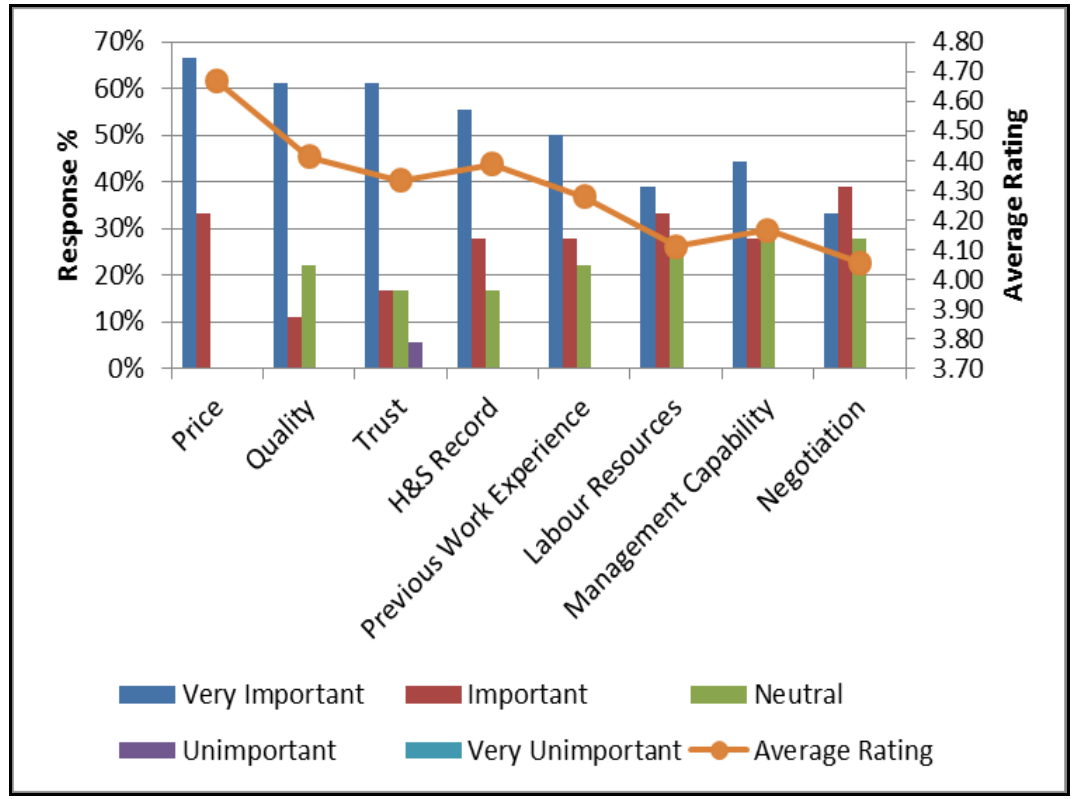

Fig. 3. Implications of SC Involvement

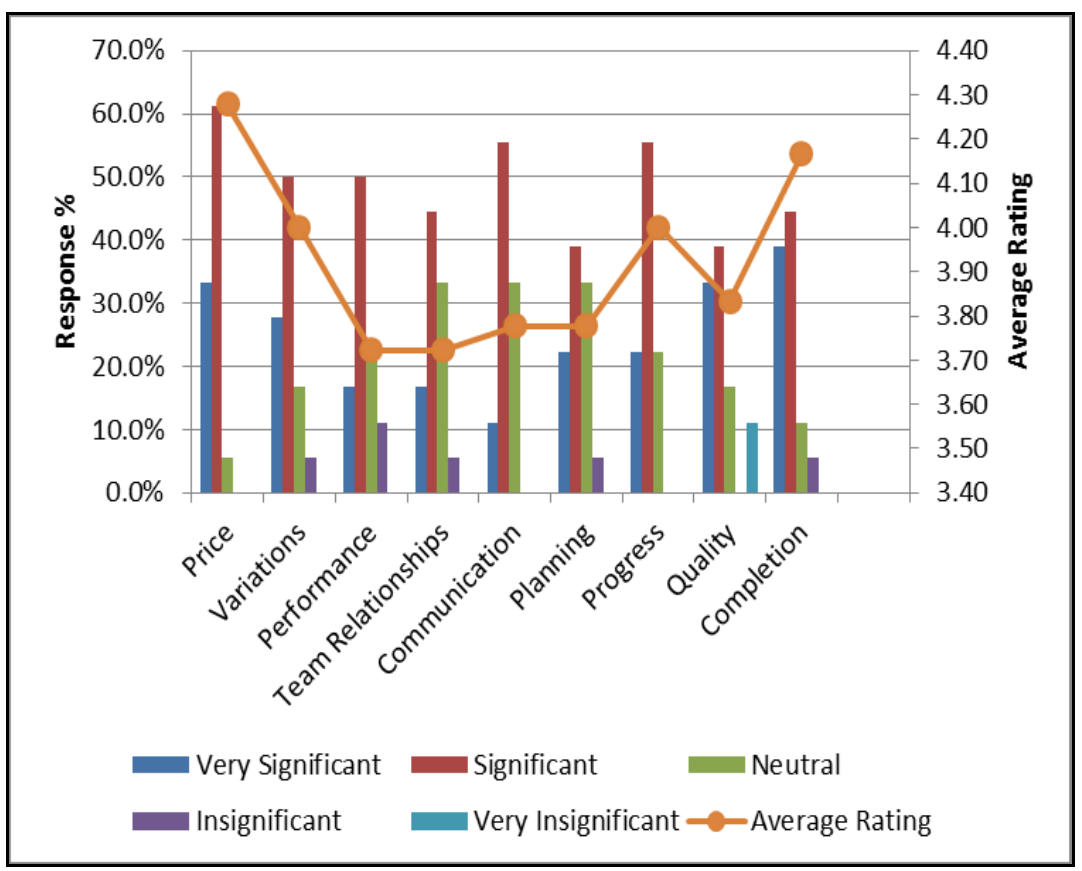

Fig. 4. Importance of factors during procurement of subcontractors

Q: Are the key personnel involved during procurement involved during construction?

The survey results revealed that $56 \%$ of SCs agreeing the key personnel are involved during procurement and construction and 44\% suggested key personnel are not involved, which is very significant too. The Case Study revealed that continuity of key personnel involved throughout procurement and construction improves information flow and successful progress on site. Although the data on this study is limited, it indicates that performance could be improved by encouraging continuity of key personnel during procurement to construction.

Q: How would you rate the importance of the following in a Main Contractor/Subcontractor relationship during procurement? (Responses; Very
Significant, Significant, Neutral, Insignificant, Very Insignificant)

With the response of very important and important ratings, Fig. 4 suggests that the main points considered by the MCs in the procurement are price, health and safety record and previous working experience. The management capability and labour resources of subcontractors are seen as less important. Also negotiation is seen as being important to influence the relationship. Majority of SCs $(61 \%)$ recognised trust, as very important for success during the procurement stage.

Q: Have you ever been restricted by the following towards a tender?

The combined responses for "always and sometimes" revealed that all of the SCs felt that they were restricted to 
provide compliant tenders. "Insufficient documentation" and "not enough time" supported the literature review finding that "documentation" and "time" provided hinders the compliant tender from the SCs. Although it is not always in the MCs control, the issue tends to be passed down to the SCs.

Interestingly, the responses from "price down the bid" indicate the lack of trust and honesty within the procurement process with $67 \%$ of SC's admitting they "sometimes" price the bid down.
Q: During the establishment of contract terms in procurement stage, how do you rate the negotiation process? (Responses; Very Fair, Fair, Neutral, Unfair, Very Unfair)

The subcontractors rated the negotiation process as fair (Fig. 6) with minority regarding as unfair or very unfair. Majority remained neutral. Amongst the SCs who see negotiation is unfair, the main impact is on price, programme and scope of work.

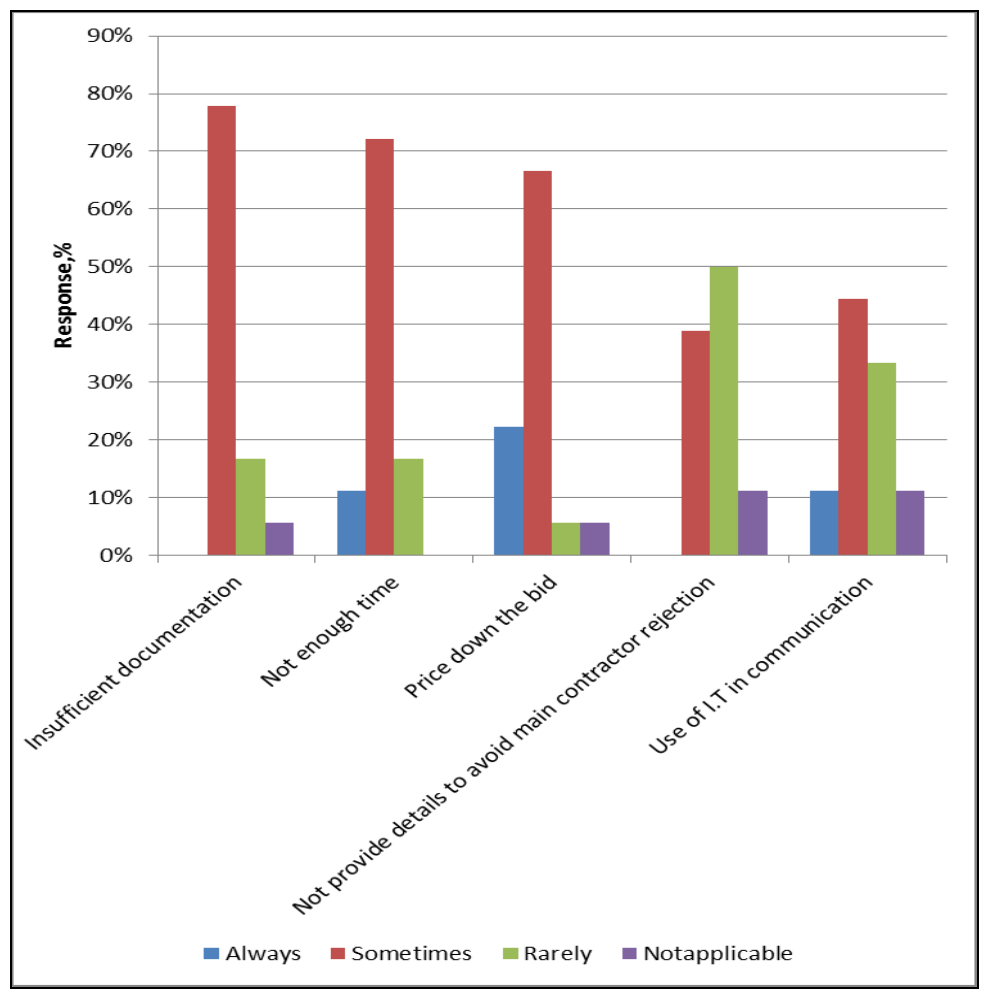

Fig. 5. Tender restrictions

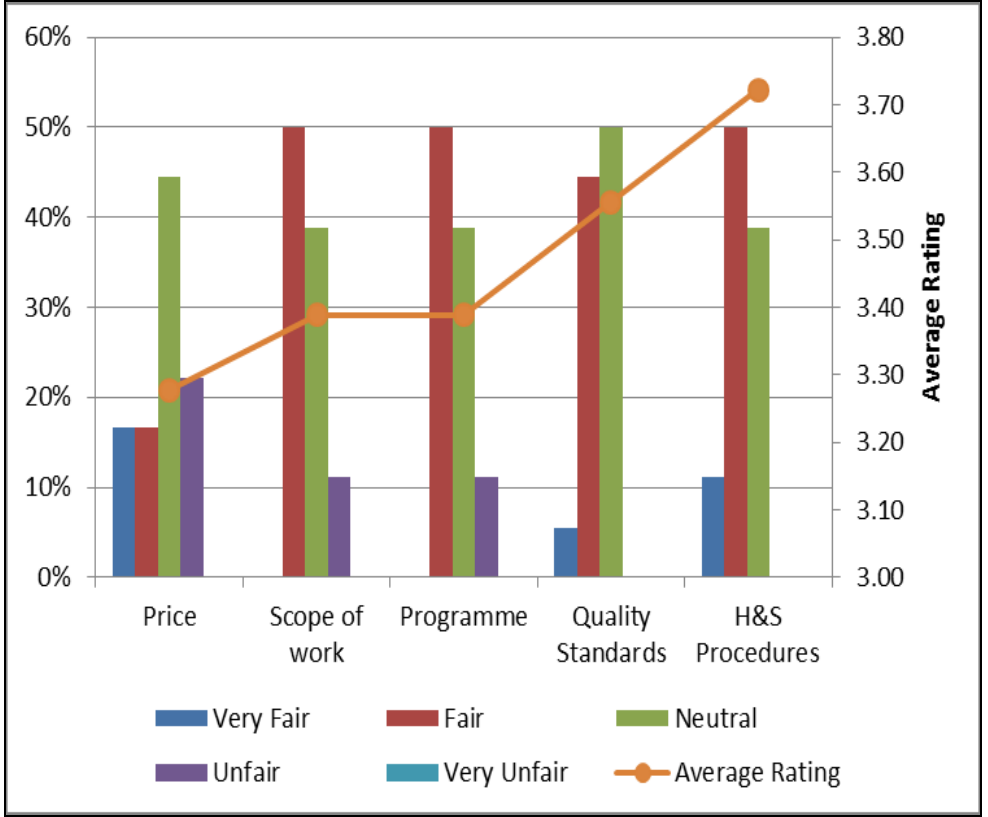

Fig. 6. Fairness rating of Negotiation process 


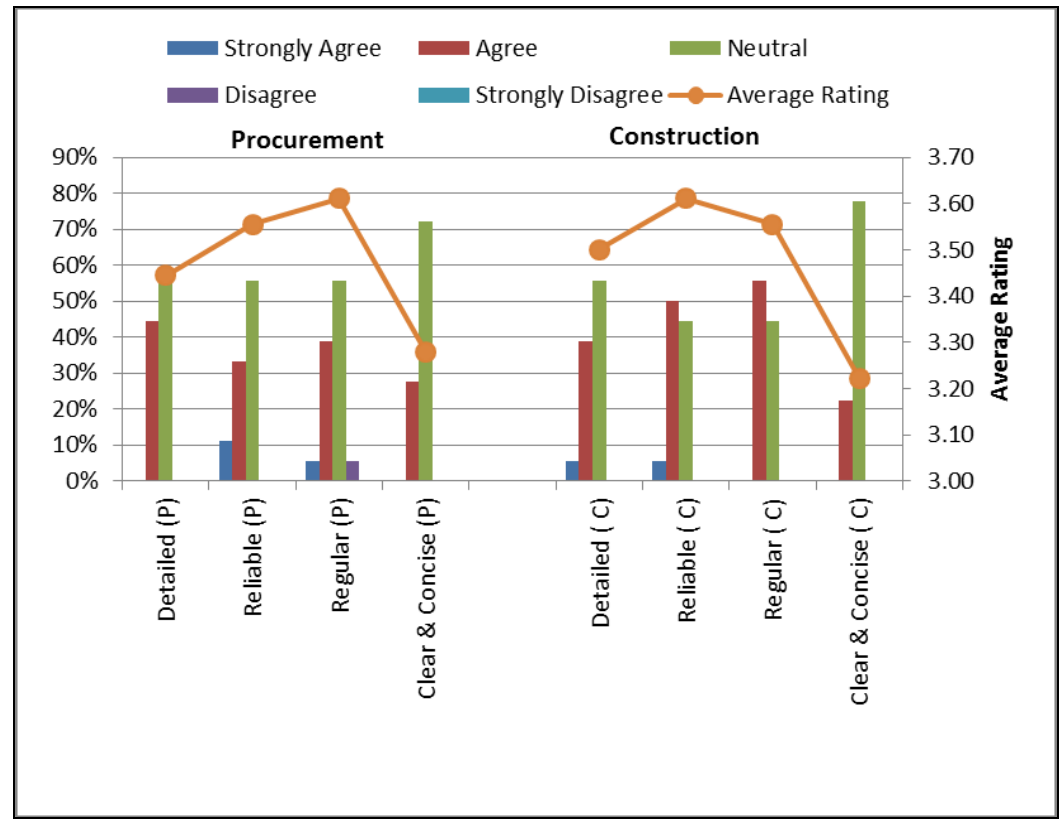

Fig. 7. Information during Procurement and Construction

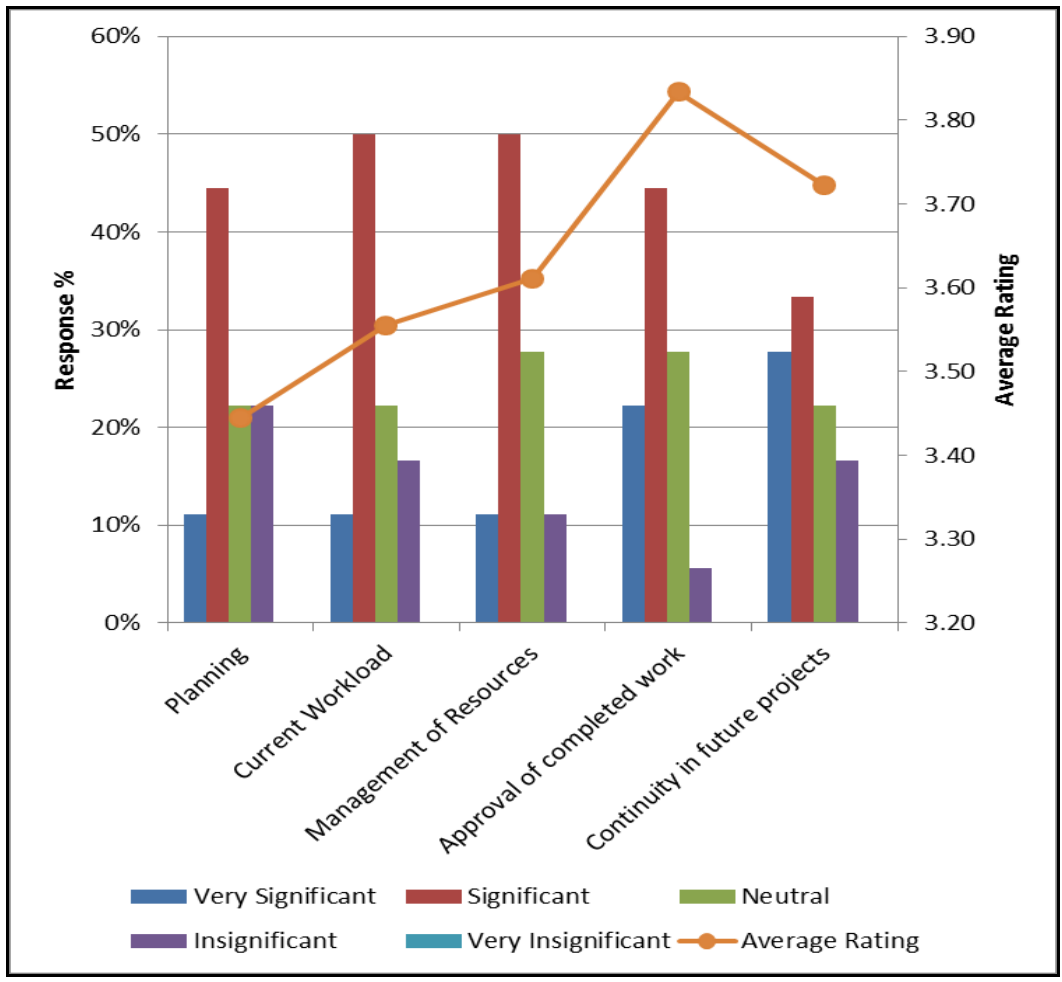

Fig. 8. Main Contractors Concerns

Q: How would you describe the information provided by the Main Contractor during procurement \& construction stage? (Individual questions for procurement and construction stage, combined response used here)

A comparison is shown in Fig. 7, between the information provided by the Main Contractor during procurement and construction. The results are similar suggesting a fairly equal information flow during procurement and construction process. The analysis describes that SCs "agree" or "neutral" to all the variables outlined in both procurement and construction. Suggesting the information flow provided by the MC could be improved, but not problematic. The average ratings (Fig. 7) confirm that details and reliability is less during procurement and frequency and clarity is better during construction as anticipated in any construction project.

$Q:$ How would you rate the Main Contractor's coordination concern towards a Subcontractor in the following aspects?

Fig. 8 outlines that the MC is mainly concerned with approval of completed work i.e. progress and quality. Other variables such as "Planning" and "Current Workload" were regarded less significant as compared to the other variables which were seen as key priority areas. 
Q: Do the pre-construction meetings with the Main Contractor cover the following aspects to ensure successful completion of projects?

During Pre-construction MCs cover the range of topics shown in Fig. 9, the most consistent meeting agendas are "Programme" and Health and Safety". While the SCs regard "Workforce Consultation" and "Other Subcontractor's Work and Relationships" as the least discussed topic during pre-construction.

Q: Which of the following information do you communicate towards your own workforce before project commencement?

The survey results define that essential information is communicated towards the SC project team (Fig. 10), specifically concerning work related specific documents. The Subcontractor Management Plan is the least likely to be given to the workforce, compared against the other documents, despite containing key information on Programme, Health \& Safety, Workforce Consultation and Exchange of Information.

Q: Do you provide proactive feedback to improve project management standards?

The analysis of responses showed that $44 \%$ of SCs surveyed provide feedback to improve project management standards, while $56 \%$ do not. The close results suggest that MCs could engage with the SC more after the project is completed to attain essential feedback that will allow them to improve.

The following section provides a critical discussion based on the findings from literature review, case study, interviews and questionnaire survey findings.

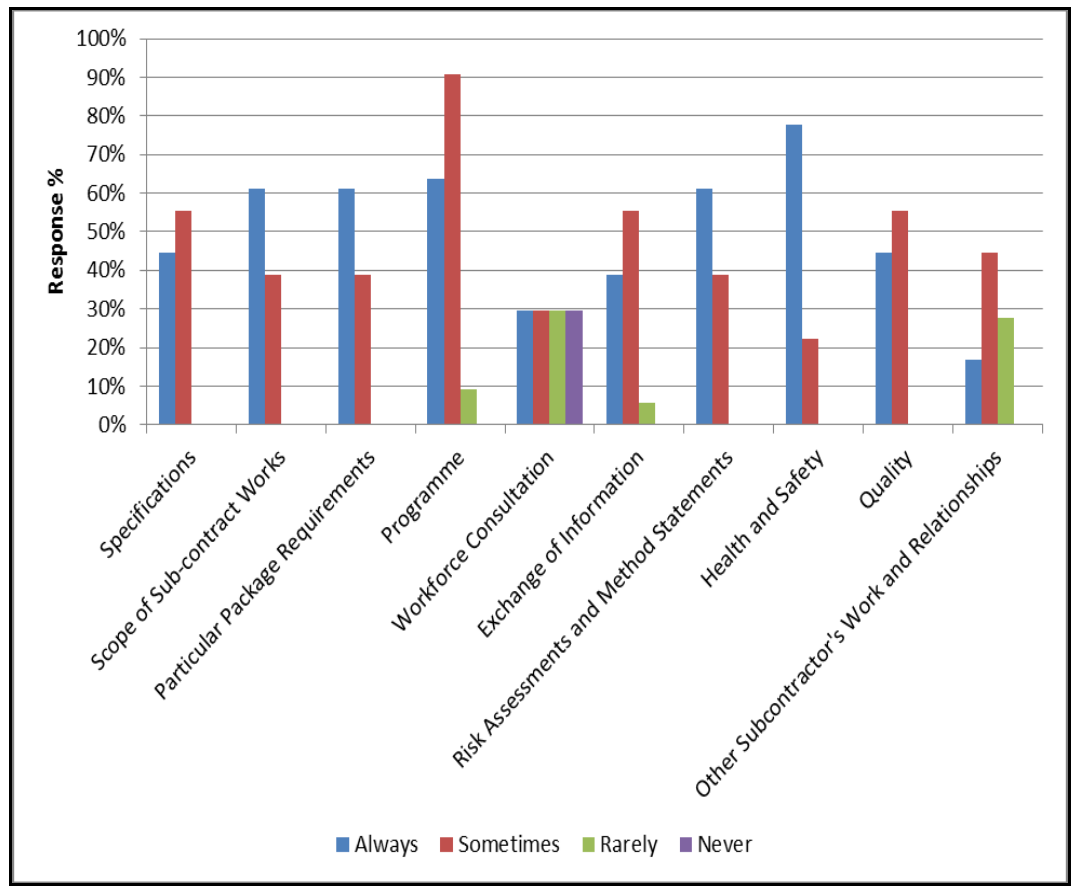

Fig. 9. Pre-construction meetings

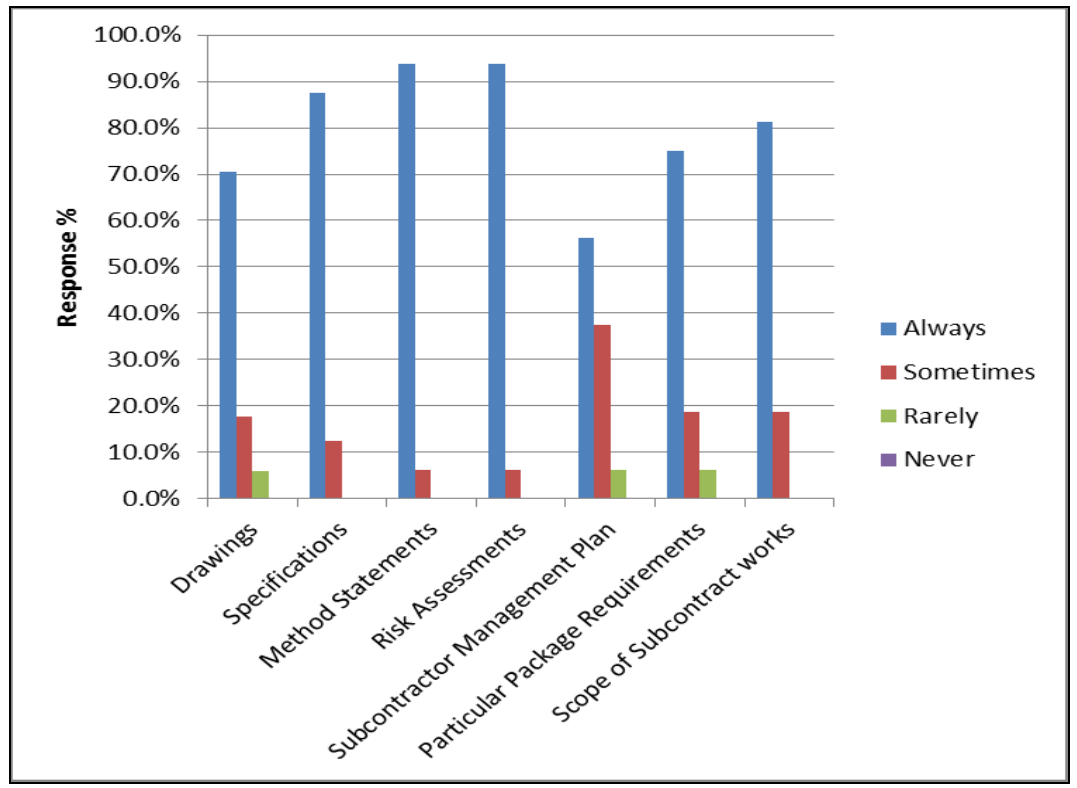

Fig. 10. Communication to Workforce 


\section{Discussions}

The literature review highlighted during procurement and construction stages, the lack of trust between the MC and $\mathrm{SC}$ resulted in time-consuming and costly formalities. During the tender process, negotiations must retain the confidence of the SCs to establish trust and maintain continuity of work in pre-construction and construction stages. The case study and semi-structured interviews revealed the lack of trust within the MC/SC relationship, resulting in a risk reduction strategy from the MC.

The Questionnaire survey analysis revealed that SCs rated the variables: price, quality and trust as very important in the $\mathrm{MC} / \mathrm{SC}$ relationship. Management capability of the SC was seen as significantly less as important, which supports findings of Hartmann and Caerteling, (2010) that MCs are willing to sacrifice the management capabilities to achieve a market-conformed price.

Despite SCs acknowledging the importance of trust to the relationship, they also indicated that price was more important because of the necessity to win work from the MC. SCs admitted to regularly pricing down the bid to win work, although the formal processes described in the case study suggest that the SC would not suggest additional items during their procurement and withheld information confirming the lack of trust within the interface, despite the literature review highlighting the MC's responsibility to ensure trust within the SCs procurement.

The questionnaire survey analysis indicated the likelihood of unfair practices by the MC in negotiation of price, scope of work and programme. While negotiation on quality standards and H\&S procedures was regarded as fair.

The survey results highlighted that the most common method of procurement strategy was to select subcontractors through open tender with price being a key factor. Although it is expected that MCs adhere to value for money principle, the price is a key consideration in awarding subcontracts. Negotiation is used to achieve the cost savings through the subcontractors and indicates the prevalence of unfair practices in the industry.

Reinforced by the semi-structured interviews, the questionnaire survey analysis revealed the restrictions to produce compliant tender due to insufficient time and lack of detailed information has as much effect as price during the preparation to tender. It should be noted that as highlighted in the literature review insufficient documentation and time during the tender process is often not always under the main contractor's control.

The semi-structured interviews and questionnaire survey highlighted that risks associated during procurement with clients are often passed down to the SC, resulting in inefficient documentation and/or information overload which in turn affects the subcontractor's ability to produce a complaint tender. In order to have successful project outcome MC's proactive approach towards risk is crucial, which was evident from the case study that MC's initiative to use own resources (time and money) to overcome design issues during construction enabled successful completion of the subcontracted work.
The literature review highlighted the importance of information flow but criticised the $\mathrm{MC}$ for poor information management. During the case study, $\mathrm{MC}$ had realised the importance of this and had acted on it to ensure information flows well. SCs also indicated that the information flow was adequate but could be improved.

The MC procurement team established the initial interface with the SC, which is continued with the Site Project team. Once contract terms had been agreed, further meetings included the site management team to discuss the project. Clearly identifying roles and attendance requirements during the pre-let meetings, obtaining the SC's support in the project was seen as crucial to the MC for success.

The questionnaire survey supported that MCs have an significant concern towards the co-ordination of the SC. The pre-construction meetings chaired by the MC covered aspects to ensure completion of the project. However, aspects regarding the SC's interface between other SCs and workforce consultation, is the least likely to be addressed.

Overall the case study project was a success for the MC, partly because the project achieved its construction programme. Although for one SC, the project was regarded as a failure, due to the short lead time given and poor quality of materials causing problems during construction.

Areas which the MC considered for improvement, was having an even stronger interface through regular meetings, enhancing communication between relevant parties and more face to face communication throughout procurement and construction. The SCs recommended more clear and concise information, consistency in workforce scheduling and longer lead times would help project performance.

Overall to improve the $\mathrm{MC} / \mathrm{SC}$ relationships, the interface requires more co-ordination with efficient communication from the MC management. Many of the prevailing adverse relationships and culture developed from a lack of trust is still affecting the construction performance. The Case Study demonstrated proactive involvement of the MC with SCs while maintaining continuity of the team throughout procurement and construction is essential for project success. It is established that there are still difficulties to achieve total honesty and trust within the MCs supply chain. However, these factors can be enhanced by MCs through development of opportunities and environment for SCs to provide complaint tenders.

As the study used a single case study approach, the findings relate to the project studied and further case studies and analysis will be required. Furthermore questionnaire survey response was limited to 18 , a wider response from across the industry supply chain would be required to generalise the findings presented in this paper. It will be worthwhile to investigate whether the MC and SC differ in their perception of the most important variables.

\section{Conclusions}

The level of involvement SCs have with an MC has a significant effect on their working relationships. Good relationships established during the procurement of the SC 
will create a better working relationship for the remainder of the project. This was proved true through a case study and semi-structured interviews. The conclusions of the study, although related to a single case study, highlight key aspects of managing interface between MC and SCs for successful completion of construction projects. Lack of trust still prevails in the industry; fear of losing the work or desperateness to win the work from the MC, SCs are not opting for openness and honesty at all times. SCs are found to be more reliant on MC's strategic management and organisation of projects. Majority of SCs, in the questionnaire survey, felt that they were restricted to provide compliant tender to the MC for different reasons such as lack of detailed documentation, inadequate time or the need to price down the bid to win the contract.

Early involvement of the SCs and adequate time given to them to tender was regarded crucial, which will not only provide right price first time but also contribute to the positive outcome of the project. The Case Study highlighted that good site management and proactive coordination by $\mathrm{MC}$ is key to solve project issues and complete the project on time. The MC, in this study, regarded face-to-face communication (not just depending on electronic communication) get to know SC before the subcontract is let as a crucial factor for successful outcome. The SCs interviewed in this study suggested that good management and coordination by the MC's site team was a key factor for the project success.

The case study highlighted that merely relying on complex procurement procedures and contractual obligations cannot provide a strong interface between the $\mathrm{MC}$ and SC. A direct approach must be adopted by MCs to challenge the relationship factors outlined within the study. Overall an enhanced communication and greater understanding will have a positive effect towards the performance in the procurement and construction stages.

\section{References}

Artto, K., Eloranta, K., and Jaakko, K (2008). Subcontracors' business relationships as risk sources in project networks. An International Journal of Managing Projects in Business, 1(1), 88-105.

Ashworth, A., (2006). Contractual procedures in the construction industry. 5th ed. Harlow: Pearson Prentice Hall.

Ballard, G. and Howell, G. (2004). Competing Construction Management Paradigms. Lean Construction Journal, 1(1), 38-45.

Bankvall, L., Bygballe, L.E., Dubois, A., and Jahre, M. (2010). Interdependence in supply chains and projects in construction. Supply Chain Management, 15(5), 385-393.

Briscoe, G. and Dainty, A. (2005). Construction supply chain integration: an elusive goal? Supply Chain Management, 10(3), 319-326.

Briscoe, G., Dainty, A.R.J., and Millett, S., (2001). Construction supply chain partnerships: skills knowledge and attitudinal requirements. European Journal of Purchasing \& Supply Management, 7(4), 243-255.

Cooke, B., and Williams, P. (2004). Construction planning, programming and control. 2nd ed. Oxford: Blackwell.

Dainty, A.R.J., Briscoe, G.H., and Millett, S.J. (2001a). Subcontractor perspectives on supply chain alliances.
Construction Management and Economics, 19(8), 841-848

Dainty, A.R.J., Briscoe, G.H. and Millett, S.J., (2001b). New perspectives on construction supply integration. Supply Chain Management: An International Journal, 6(4), 163-73.

Das, T.K. and Teng, B.-S. (1998). Between trust and control: developing confidence in partner cooperation in alliances. The Academy of Management Review, 23(3), 491-512.

Egan, J. (1998). Re-thinking construction: The Construction Best Practice.

Fearne, A. and Fowler, N., (2006). Efficiency versus effectiveness in construction supply chains: the dangers of lean thinking in isolation. Supply Chain Management: An International Journal, 11(4), 283287.

Fryer, B., Egbu, C., Ellis, R., and Gorse, C. (2004). The practice of construction management. 4th ed, Oxford: Blackwell.

Hadaya, P. and Pellerin, R. (2010). Determinants and performance outcome of manufacturing SMEs use of internet-based IOISs to share inventory information. International Journal of Electronic Business. 8(6), 477-504.

Hartmann, A., and Caerteling, J. (2010). Subcontractor procurement in construction: the interplay of price and trust. Supply Chain Management, 15(5), 354-362.

Humphreys, P., Matthews, J., and Kumaraswamy, M., (2003). Pre-construction project partnering: from adversarial to collaborative relationships. Supply Chain Management: An International Journal, 8(2), 166-178.

Jamieson, M., Thorpe, A., and Tyler, A. (1996). Refocusing collaboration technologies in the construction value system. Proceedings of the CIB W78 Conference Construction on the Information Superhighway, Slovenia, April, 279-89.

Latham (1994). Constructing the team - "The Latham report". Department of the Environment, HMSO, London.

Loosemore, M., Nguyen, B. T., and Denis, N. (2000). An investigation into the merits of encouraging conflict in the construction industry. Construction Management and Economics, 18, 447-456.

Love, P.E.D., Irani, Z., and Edwards, D.J. (2004). A seamless supply chain management model for construction. Supply Chain Management: An International Journal, 9(1), 43-56.

Mawdesley, M., Askew, W., and O'reilly, M. (1998). Planning and controlling construction projects : the best laid plans. Chartered Institute Of Building (CIOB). Harlow : Ascot: Longman.

McCord, J. (2010). Subcontractor perspectives: Factors that most affect their relationships with general contractors- A pacific Northwest study. PhD thesis. School of Architecture and Construction Management, Washington State University, [online] http://spokane. wsu.edu/academics/Design/ResearchService/P_McCo rd_042110.pdf, accessed on 24 March 2012.

McGeorge, D. and Palmer, A. (1997). Construction Management : New Directions. Oxford: Blackwell Science.

Mclvor, R., Humphreys, P., and McAleer, E. (1997).Implications of partnership sourcing on buyer supplier relations. Journal of General Management, 23(1), 53-70. 
Miller, C., Packham, G., and Thomas, B. (2002). Harmonization between MCs and SCs: a prerequisite for lean construction? Journal of Construction Research, 3(1), 67-82.

Moody, C., Riley, M., and Hawkins, N. (2008). Differentiation of Sub Contract Organisations and Principal Contract Organisations; though attribute analysis. RICS COBRA construction and building research conference, Dublin.

Muya, M., Price, A.D.F., and Thorpe, A. (1999). Contractor's supplier management, In Bowen, P. and Kindle, R., eds. Proceedings of CIB W55165 Joint Triennial Symposium, Customer Satisfaction: A Focus for Research and Practice in Construction. 5-10 September, Cape Town.

Ndekugri, I.E. and McCaffer, R. (1988). Management Information Flow in Construction Companies. Journal of Construction Management \& Economics, 6(4), 273294.

Odeyinka, H. and Kelly, S. (2009). An evaluation of the budgetary reliability of bills of quantities in building procurement. RICS COBRA Research Conference, University of Cape Town, 435-446.

Okunlola, O. S. and Johnson, I. I. (2013). Determining the Performance of Procurement Methods against Selection Criteria using Outranking - Satisfying Methodology. Journal of Engineering, Project, and Production Management, 3(2), 74-84.

Segerstedt, A. and Olofsson, T. (2010). Supply Chains in the Construction Industry. Supply Chain Management, 15(5), 347-353.

Thorpe, A., Dainty, A.R.J., and Hatfield, H. (2003). The realities of being preferred: specialist SC perspectives on restricted tender list membership. Journal of Construction Procurement, 9(1), 47-55.

Wolstenholme, A. et al. (2009). Never waste a good crisis: a review of progress since Rethinking Construction and thoughts for our future. London: Constructing Excellence.

Xie, C., Dash, W., Jianwen, L., and Xiaoling, H. (2010). A Case Study of multi-team communications in construction design under supply chain partnering. Supply chain Partnering, 5(5), 363-370.

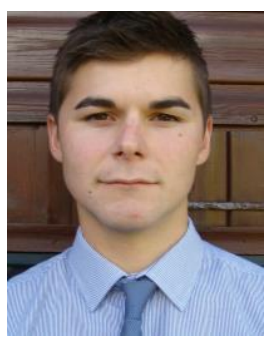

Harry Richard White is a Construction Manager, working for Mansell Constructions Services Ltd. Graduated from Southampton Solent University with a BA (Hons) in Construction Management in 2012. $\mathrm{He}$ is a Incorporate Member of Chartered Institute of Buildings (ICIOB) and a Chairman of the Hampshire CIOB Novus Group. His interests include construction project management, specifically subcontractor interface management.

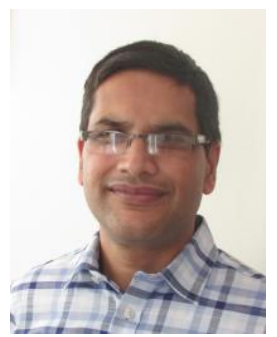

Dr Ramesh Marasini is an Associate Professor in Maritime and Technology Faculty, Southampton Solent University. He is a Member of Chartered Institute of Buildings and a fellow of Higher Education Academy. He leads Research Project, Construction Management and Project Management units in Built Environment courses. He has written several journal and conferences papers and serves as reviewer of various international journals. He is actively involved in research in the field of Simulation Modelling, Project Management and Construction Information Technology applications.

\section{Appendix 1: Semi-structured Interview Questions}

1. How many years have you been in your current position, are you frequently involved with Subcontractors and what is your specialisation?

2. Can you explain how you were involved, during the procurement process? (Selection, appointment, what stage of the project)

3. During the tender process, what information was communicated to provide a tender price?

4. Was there any change in documents provided during the tender up to the construction stage from the Main Contractor?

5. During the tender process were you involved in any negotiations, if was conducted? (Please explain who was involved and the topic of negotiation)

6. Once the contract terms are agreed, how did you proceed in developing strategies to progress with the project? (For example, selection methods, communication of documents)

7. How did you identify roles and responsibilities of your team to deliver the scope of the project?

8. What documents/information was communicated to the team to progress with the project?

9. Did you have the people involved in tender stage, involved during the construction stage?

10. Did you complete the project on time, according to schedule and within the budget, what are the reasons?

11. Were there any areas that could have been improved by the Main Contractor to enable you to progress more smoothly?

12. How do you decide procurement strategy for Subcontractors? (Main Contractor only)

13. What are the important factors to a Main Contractor /Subcontractor relationship? 